\title{
Mechanical Behaviour of E -Glass and Aluminium Hybrid Composite
}

\author{
Saroj Kumar ${ }^{1}$, Keshav Kumar Jha ${ }^{2}$ \\ 1,2 Mechanical Engineering Department, KCC Institute of Technology and Management, Gr Noida, UP, India
}

\begin{abstract}
The mechanical behavior of the E-Glass and Aluminum Hybrid composite is the subject of this research. A large number of writings has been referred in this regard, and it takes been discovered that dispensation circumstances dismiss remain adjusted to obtain Alcomposites construction. E GLASS and Aluminum mixture composites remain a modern group of the metal matrix composites with an ability to meet the needs of specialized manufacturing submissions. Aluminum mixture strengthening technology is a solution to the diverse and the ever-increasing service needs of an industries such by way of aviation, aerospace, automobiles, and a maritime, among others. These requirements are fulfilled thanks to better mechanical properties, the ability to manufacture aluminum hybrid composites using traditional methods, and the prospect of lowering production costs. Meanwhile of the manufacturing constraints are linked to the strengthening particulates, the efficiency of these products is largely reliant on choosing the correct mix of reinforcing materials. The results of this study show that E-Glass and Al-based hybrid composites have a lot of potential as a replacement for earthenware reinforced compounds and unreinforced Al-alloys in a variety of locomotive submissions that require low cost, in height strength-to-mass ratio, and greater dress confrontation. Finite element analysis was used to perform mechanical possessions such as tensile and impact tests (Ansys workbench 19.2)
\end{abstract}

Keywords—mechanical behavior, finite element approach, Aluminum Matrix Composites (AMCs)

\section{INTRODUCTION}

For mechanical and wear uses, aluminium alloys are a valuable engineering material. the density, increased machinability, a high detailed strength, greater apparel resistance, and low thermal conductivity make it ideal for a variety of applications. The automotive, aerospace, shipping, and mineral mining sectors all use aluminium alloys. The addition of a solid ceramic step toward a comparatively soft matrix alloy, such as aluminium, increases the alloy's strength, creep resistance, and wear resistance. The aluminium alloy 6061-T6 is commonly used in aircraft.[3]

Because of its high strength, light weight, and better corrosion resistance, it is used in military vehicles and marine environments. Aluminium-based composites are one of the most commonly used composites (Aluminium Matrix Composites). The Aluminium matrix composites (AMCs) remain a type of high-performance, light-weight aluminium centric material. Incessant or intermittent fibres, whiskers, or particulates with capacity segments reaching between a few hundred to $70 \%$ may be used as reinforcement in AMCs. [7,18]

Chemical wildernesses such as a rice husk residue, ashes of coconuts shell, and fuel ash of a palm oil, fly ash, and sugarcane bagasse have been added to common reinforcements in aluminium matrix composites. Carbides, borides, nitrides, and alumina are among the ceramic compounds used as reinforcement. In aluminium-based composites, these have remained stated to achieve wanted physical and mechanical properties. Because of its strong asset-to-weight ratio, increased stability, reasonably extraordinary temperature properties, regulated the thermal expansion coefficient, and improved and optimized electrical properties, aluminium matrix composites (AMCs) have piqued attention in aerospace, defines, and an automotive application. [12] Physical Vapour Processing (PVD) method, Direct Processing/Spray Deposition technique, Rock-hard State technology's, Fluid State technology's, Precipitate technology,
Metallurgy technology's, a Physical Vapour Dispensation (PVD) technology. While previous research has been done and published in the literature on the development of mixture composite possessions such as mechanicals (rigidity, weariness resistances), a physical and the chemical finished traditional complexes. However, the approaches used and the outcomes achieved are not the same. The ultimate result suggests that the basic properties should be improved.[9]

This effort offerings a cautious and organizational appraisal of present everything on the properties of hybrid reinforcements aluminium alloy's mechanicals, the physical, chemical property.

\section{A. Reinforcing materials in aluminium matrix hybrid composites}

Strengthening material in AMC the dissimilar reinforcing's material recycled in a expansion of AMC can be confidential into 3 comprehensive group, which remains a artificial ceramics the particulate, manufacturing wildernesses and the agricultural the waste derivative. Final properties of mixture reinforcements be contingent on separate possessions of a reinforcement nominated and matrix alloys, A dispensation way accepted for the manufacturing AMC be contingent on the natures of a matrix alloys and strengthening resources which also inspiration, the finals possessions of AMCs

This is due to the fact that the reinforcement materials are bound to the majority of the criteria considered during the construction of AMCs. Reinforcement form, height, density, yield strength, hardness, and matrix delivery are a few examples of such parameters. The debate on the reinforcement combinations use in the mixture of hybrid AMCs is separated into 3 broad classes based on the published papers reviewed. There are composite AMCs that mix 2 artificial ceramic material, an agricultural -waste derivatives.as well as agricultural waste and synthetic reinforcement. 


\section{B. Hybrid AMC through 2 dissimilar artificial ceramic materials}

In subcategory of mixture AMCs is designed primarily for presentation enhancement, with a smaller amount importance on cost. Silicon carbide and materials that have remained tested, nonetheless silicon carbide and alumina remain the most widely used. Traditional AMCs strengthened with Sic or Al2O3 outperform monolithic alloys in terms of strong point and basic stiffness, but at the cost of ductility, crack durability. Material properties such as ductility and fracture durability are significant.

According to studies released in the past, the corrosion presentation of these AMC is likewise not reliable. For property optimization, this has demanded the uses of 2 or 3 plastic reinforcing's particulate. To improve the efficiency of AMCs, graphite and Boron carbide need remained second-hand in conjunction with Sic The following are some of the conclusions from recently available papers.

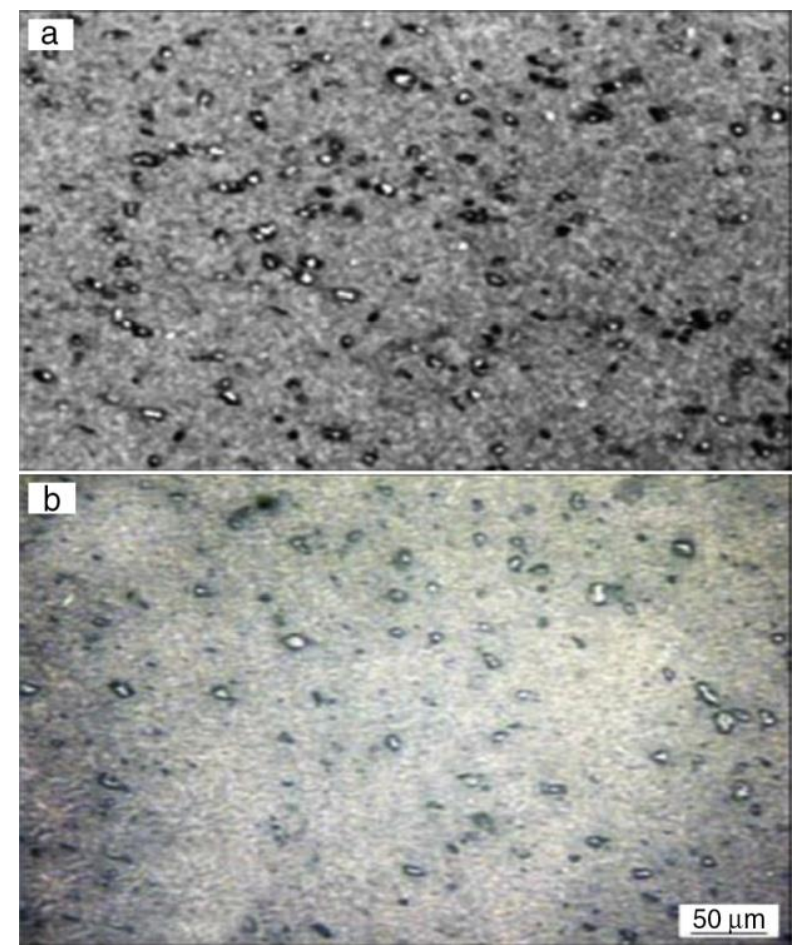

Figure 1. Microstructure of surface

\section{(a) $\mathrm{Al}_{2} \mathrm{O}_{3}$}

Wear properties of friction tested AL 6061-T6 composite material, the effects of $\mathrm{Sic} / \mathrm{Gr}$ and $\mathrm{Sic} / \mathrm{Al} 2 \mathrm{O} 3$ were investigated. The authors stated that the reinforcement materials were distributed uniformly in the nugget region of AMC, as seen in Figure. 1. The writers also made a similar study on hybrid AMCs comprising $\mathrm{SiC}$ and A12O3[33]. The hybrid composites outperformed the matrix material in terms of stiffness and wear resistance. Furthermore, the hardness of material varying depends upon the composition of materials, its strength and physical and chemical Properties.

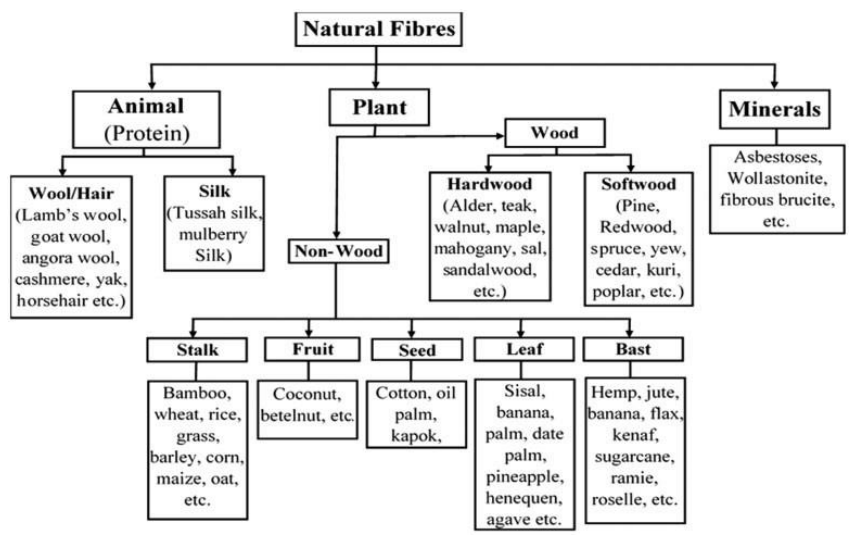

Figure 2. Classification of natural fibres

TABLE I

MECHANICAL BEHAVIOUR OF ALUMINUM HYBRID COMPOSITE

\begin{tabular}{|c|c|c|c|}
\hline $\begin{array}{l}\text { S. } \\
\text { No }\end{array}$ & $\begin{array}{l}\text { Aluminium } \\
\text { Matrix's Use }\end{array}$ & $\begin{array}{l}\text { Reinforcement } \\
\text { used }\end{array}$ & $\begin{array}{l}\text { Mechanical Behaviour } \\
\text { of a Hybrid Composites }\end{array}$ \\
\hline 01 & Al 2024 & $\begin{array}{l}\text { Silicon Carbide } \\
\text { and Graphite }\end{array}$ & $\begin{array}{l}\text { In contrast to } \\
\text { unreinforced } \\
\text { aluminium, } \\
\text { hybrid metal matrix } \\
\text { composite is lighter } \\
\text { and has increased } \\
\text { hardness, tensile } \\
\text { strength, } \\
\text { decreased } \\
\text { elongation. } \\
\text { elastic modulus and } \\
\text { tensile strength of } \\
\text { graphite decrease as } \\
\text { the volume fraction } \\
\text { and particle size } \\
\text { increase. }\end{array}$ \\
\hline 02 & $\begin{array}{l}\mathrm{Al}-\mathrm{Mg}-\mathrm{Si} \\
\text { alloy }\end{array}$ & $\begin{array}{l}\text { Silicon Carbide } \\
\text { and bamboo } \\
\text { leaf ash }\end{array}$ & $\begin{array}{l}\text { With increasing } \\
\text { bamboo leaf ash } \\
\text { (BLA) material, the } \\
\text { hybrid composites' } \\
\text { hardness, ultimate } \\
\text { tensile strength, and } \\
\text { percentage } \\
\text { elongation decrease. }\end{array}$ \\
\hline
\end{tabular}

The mechanical behaviour of composite materials has also been found to be influenced by the texture of reinforcement.

The tensile strength and elastic modulus of $\mathrm{Al} / \mathrm{Sic} / \mathrm{Gr}$ hybrid composites manufactured by squeeze casting are found to decrease as the volume fraction and particle size of graphite increases. Designing low-cost - highperformance $\mathrm{Al}$ matrix hybrid composites with bamboo leaf ash (an agro waste ash) and silicon carbide as complementary reinforcement

is shown in reference [15]. The findings show that as the amount of bamboo leaf ash (BLA) in the hybrid composites increases, The hybrid composites' hardness, ultimate tensile strength, and percentage elongation 
decrease. The basic strength of the hybrid composite, on the other hand, is comparable to that of the single reinforced composite of $2 \mathrm{wt}$. present BLA.

The fracture resistance of the hybrid composite, on the other hand, is superior to the $\mathrm{Al} 10 \mathrm{wt} \% \mathrm{SiC}$ composite with single reinforcement. The mechanical properties of aluminium hybrid composites with various rice husk ash volume fractions (RHA) and Silicon Carbide Particulate in equivalent proportions are studied in the reference. If the Reinforcement capacity fraction increases when the density reductions, the hardness besides porosity of the hybrid composites increases. In addition, the ultimate tensile strength and yield strength growth, but elongation decreases. The increase in dislocation density is usually attributed to the increased strength of mixed composites.

If the capacity fraction of rigid reinforcement in the soft matrix upsurges, the hardness increases. The heat behaviour of hybrid composites has a significant impact on their micro stiffness as compared to those that have not been heat treated. As compared to the matrix alloy, the micro hardness of Al6061 composites is found to be developed. Heat treatment is said to encourage a more uniform grain structure, lowering porosity and increasing hardness. The outcome of heat handling parameter on the attire behaviour of aluminium composites is studied in this reference. The volume damage of heat-treated composites is observed to decrease with increasing aging time, revealing a minimum volume loss.

\section{Tribological properties}

Aluminium hybrid composites have been shown to have a lower wear rate than binary composites. Different types of aluminium matrices and manufacturing techniques have also been used. Determine behaviour in aluminium composites. Table II shows aluminium matrix, reinforcement and tri biological behaviour observed in some aluminium composites.

TABLE II

TRIBOLOGICAL BEHAVIOUR OF HYBRID COMPOSITE

\begin{tabular}{|c|l|l|l|}
\hline S. & $\begin{array}{l}\text { Aluminium } \\
\text { Matrix } \\
\text { Used }\end{array}$ & \multicolumn{1}{|c|}{ Reinforcement used } & $\begin{array}{l}\text { Tribological } \\
\text { Behaviour of } \\
\text { Hybrid } \\
\text { Composite }\end{array}$ \\
\hline 01 & $\begin{array}{l}\text { AA6061 } \\
\text { alloy }\end{array}$ & $\begin{array}{l}\text { Saffil and Silicon Carbide } \\
\text { particles Low wear rate. } \\
\text { Silicon Carbide } \\
\text { Particles and graphite/an } \\
\text { trisulphide Clothing rate } \\
\text { reductions with increase in } \\
\text { weight with enlarged speed } \\
\text { and low } \\
\text { coefficient, low } \\
\text { temperature rise and low } \\
\text { noise level } \\
\text { confrontation } \\
\text { under dry } \\
\text { descending at } \\
\text { raised temperature } \\
\text { and } \\
\text { high weight } \\
\text { likened to } \\
\text { monumental } \\
\text { composite }\end{array}$ \\
\hline 02 & $\begin{array}{l}\text { Al-12Si } \\
\text { alloy }\end{array}$ & $\begin{array}{l}\mathrm{Al}_{2} \mathrm{O}_{3} \text { and Carbon } \\
\text { Fibres }\end{array}$ & $\begin{array}{l}\text { When } \\
\text { volume fraction } \\
\text { of carbon fibre } \\
\text { is increased, the } \\
\text { wear } \\
\text { reduces. }\end{array}$ \\
\end{tabular}

\begin{tabular}{|c|c|c|c|}
\hline 03 & AA6061 & $\begin{array}{l}\text { Silicon Carbide and } \\
\text { Graphite }\end{array}$ & $\begin{array}{l}\text { Wear declines with } \\
\text { increasing } \mathrm{SiC} \\
\text { content up to } 20 \% \text {, } \\
\text { but improves with } \\
\text { higher } \mathrm{SiC} \text { and } \\
\text { Graphite content. } \\
\text { The wear } \\
\text { resistance of } \\
\text { hybrid composites } \\
\text { improves as the } \\
\text { graphite particle } \\
\text { size increases. }\end{array}$ \\
\hline 04 & $\begin{array}{l}\mathrm{Al} 6061 \\
\text { alloy }\end{array}$ & $\begin{array}{l}\text { Silicon Carbide and } \\
\text { Nickel coated } \\
\text { Graphite }(\mathrm{Gr}-\mathrm{Ni})\end{array}$ & $\begin{array}{l}\text { If the percentage } \\
\text { of } \mathrm{Gr}-\mathrm{Ni} \text { addition } \\
\text { rises, so does the } \\
\text { friction coefficient. } \\
\text { Both composites } \\
\text { with Gr-Ni adds } \\
\text { have similar wear } \\
\text { speeds. } \\
\text { wear levels of base } \\
\mathrm{Al} / \mathrm{SiC} \text { content } \\
\text { without Gr- } \\
\text { The addition of } \\
\text { nickel to the A356 } \\
\text { alloy, as well as } \\
\text { silicon carbide and } \\
\text { graphite, leads to } \\
\text { improved } \\
\text { performance. }\end{array}$ \\
\hline
\end{tabular}

During dry sliding, the wear behaviour of an aluminium alloy reinforced with silicon carbide particles and graphite/antimony trisulphide is studied (Sb2S3). The first is a binary composite of $\mathrm{Al}$ with $20 \%$ Silicon Carbide particles ( $\mathrm{Si} \mathrm{Cp}$ ), and the second is a hybrid composite in solid state of Al with Si Cp and solid lubricant (Graphite + $\mathrm{Sb} 2 \mathrm{~S} 3)$.

In general, the wear rate reduces as the load grows, but increases as the speed increases, as long as the friction coefficient is minimal, the temperature rises slowly, and there is no noise. With a blocky and smooth worn surface, the hybrid composites have appropriate characteristics. The dress behaviour of the AA6061 + 11 vol. present Saffil $+20 \%$ Sic, AA6061 +60 vol. present Sic) is investigated. The highest wear confrontation in contradiction of P400 Sic grit adhesive attached paper was found in composites of AA6061/11 present Sic

When compared to BS817M40 (EN24) steel, AA6061 present Saffil and AA6061/20 present SiC show minor changes. Though, the 60 present SiCp/AA6061 composites and the combination of AA6061/11 present Saffil/20 present $\mathrm{SiCp}$ composites both have poor wear rates. When compared to $\mathrm{Al} / \mathrm{Saffil}$ and $\mathrm{Al} / \mathrm{Saffil} / \mathrm{Al} 2 \mathrm{O} 3$, hybrid aluminium composites covering Saffil/SiC have shown to require greater uniform confrontation beneath dry descending at high temperatures and loads.

Under light load and at room temperature, the dominant uniform instrument is abrasive, but as load or temperature rises, the leading wear mechanism shifts to adhesive. $\mathrm{Al}$, on the other hand, has the best wear resistance among them when lubricated. Micro ploughing is the most common wear process for composites, with microcracking often occurring often. The Al-12Si alloy 
reinforced with 12 vol. present $\mathrm{Al} 2 \mathrm{O} 3$ composites in Reference display a dangerous change throughout packing from moderate to extreme clothing between 196 and 245. The monumental Al-12Si alloy, on the other hand, has a range of 147 to $196 \mathrm{~N}$. Furthermore, the calculation of 4 present carbon small fibres to the 12 present Al2O3/Al$12 \mathrm{Si}$ composites improves the performance.

Under light load and at room temperature, the leading uniform instrument is rough, but as load or temperature rises, the leading wear mechanism shifts to adhesive. $\mathrm{Al} / \mathrm{Saffil}$, on the other hand, has the best wear resistance among them when lubricated. Micro ploughing is the most common wear process for composites, with microcracking often occurring often. The Al-12Si alloy reinforced with 12 vol. present $\mathrm{Al} 2 \mathrm{O} 3$ composites in Reference display a dangerous change throughout packing from moderate to extreme uniform between 196 and 245 . The monolithic Al-12Si alloy, on the other hand, has a range of 147 to $196 \mathrm{~N}$. Furthermore, the calculation of 4 percent carbon small fibre to the 12 present Al2O3/Al12Si composites improves the performance.

The vital transition temperature for composites bonded with just 12 vol. percent $\mathrm{Al} 2 \mathrm{O} 3$ fibre improves between 250 and $300 \mathrm{oC}$, while the monolithic aluminium alloy improves between 150 and $200 \mathrm{oC}$. However, in the region of $350-400 \mathrm{oC}$, the dangerous changeover temperature of composites strengthened with $\mathrm{Al} 2 \mathrm{O} 3$ and carbon fibres increases even further. The wear rate of 12 vol. present composites declines as the thickness fraction of carbon fibre increases to 6 vol. percent. The clothing mechanisms of Al-12Si alloys are not affected by reinforcement fibres, according to an investigation of worn exteriors and subsurface areas. Extreme adhesion becomes the primary wear mechanism.

On the basis of the AA6061 alloy the materials that make up the composites have a graphite content of 9 percent and a $\mathrm{SiC}$ content of 0 to 40 percent. Sliding lengths of 250 , 500,750 , and 1000 meters are included. Wear is observed to decrease with increasing declines as the Sic content increases, with a smallest value of $30 \mathrm{vol}$. present Sic and an improvement after that. According to reference, the addition of resistance of Sic/Al Significantly increased the confrontation of Sic/Al complexes by 170-340 times. Furthermore, uniform loss of counter face steel is reduced through a margin of around two-thirds. The uniform confrontation of $\mathrm{SiC} / \mathrm{Grp} / \mathrm{Al}$ compounds rises as the graphite particle size decreases. The increase in uniform confrontation is mostly due to the

Improvement of the lubrication tribe-coating, which is made up of a multifaceted combination of iron oxides, graphite, broken Sic crystals, and several small aluminium particles. Investigates the behaviour of $\mathrm{Al} / \mathrm{SiC} / \mathrm{Ni}$-coated graphite $(\mathrm{Gr}-\mathrm{Ni})$ hybrid composites synthesized using the semisolid powder densification process with various quantities of $\mathrm{Gr}-\mathrm{Ni}$ addition. The $\mathrm{SiC}$ and nickel-coated graphite $(\mathrm{Gr}-\mathrm{Ni})$ particles in the aluminium matrix are said to be distributed evenly. In complexes with covered Gr-Ni particles, graphite agglomeration was reduced

Addition is a verb that means to add something. All of the composites with $\mathrm{Gr}-\mathrm{Ni}$ adds have a higher wear rate than the base $\mathrm{Al} / \mathrm{SiC}$ substance without any $\mathrm{Gr}-\mathrm{Ni}$ inclusion.
As a result, graphite-based composites are not ideal for wear reduction because the degradation of mechanical properties outweighs the limited gain infraction reduction. Metal matrix composites with a zinc/aluminium alloy (ZA) matrix are becoming more common as light-weight and wear-resistant materials.

\section{OBJECTIVE AND METHODOLOGY}

A. Study the mechanical behaviour of e-glass and aluminium Hybrid composite exhausting FEM

B. Static linear structural analysis of e-glass and aluminium Hybrid composite

C. Study the Hardness behaviour of e-glass and aluminium Hybrid composite using finite element method

\section{FINITE ELEMENT APPROCH}

The FEM is a popular method for numerically solving a wide ranges of engineering problem. Under a number of boundary and loading conditions, the method can handle any complicated shape or geometry, as well as any material. The generality of the finite element approach is well adapted to the research. It's also a valuable modeling tool that helps designers to perform parametric design studies by contemplating and evaluating various design scenarios (different shapes, textures, weights, and so on).

\section{STEP-BY-STEP}

Step 1: Modelling is the process of creating an object's geometry, which is nothing more than a computer-readable mathematical definition. The mathematical model aids in viewing the image of the object created and manipulated on the graphical terminal by executing various program commands through the CPU and input devices.

Step 2: Spectrum description (Structure).

The FEM first step is to separate the solution region's composition into sub divisions or components.

Step 3: Choose an appropriate interpolation model

Step 4: Element stiffness matrix derivation

The element's stiffness matrix $[\mathrm{K}(\mathrm{e})]$ and load vector $\mathrm{P}(\mathrm{e})$ must be calculated from the assumed displacement model, either using equilibrium conditions or a suitable Variation theory.

Step 5: Putting together the element equations to get the equilibrium equations.

Step 6: Strictly enforcing the boundary restrictions Unless boundary conditions are substituted, the equations produced cannot be solved. The geometry boundary conditions result from the fact that displacement can be articulated at the body or structure's borders or as an impact.

Step 7: Solve the machine equation to find nodal displacement values.

The cumulative equilibrium equations must be modified to account for the problem's boundary conditions. After the 
boundary conditions are taken into account, the equilibrium equations can be expressed as

$$
[\mathrm{K}] \varphi=\mathrm{P}
$$

Step 8: If applicable, the element strains and stresses can be calculated using solid or structural dynamics equations based on the known nodal displacements. The terms in brackets in the preceding steps follow the general FEM step-by-step protocol.

\section{Convergence requirement}

A numerical approach to a complex problem is given by the finite element method. As a result, it's reasonable to assume that the solution would converge to the structure's exact formulation. As a result, as the mesh is smoother, the solution can converge to the right result, which will be done if the assumed displacement equation met the following three conditions. Inside the element, the displacement function must be constant. This condition can be conveniently met by using polynomials in the displacement model. The displacement feature must be able to reflect the element's rigid body displacement. When the nodes are given a rigid displacement, this is what it means.

The factor does not undergo rigid body motion, which results in zero nodal forces. This is generally ensured by the constant terms in the polynomials used for displacement models. Inside the element, the displacement function must be capable of representing constant strain states. Imagine a situation in which the body or form is separated into bigger and smaller parts. This is the reason for the necessity. If the size of these elements approaches infinity, the tension in each element approaches infinity as well.

The linear terms present in the polynomials fulfil the condition for one, two, and three-dimensional elasticity problems. However, instead of constant strains, constant curvature is used.

\section{Advantages of FEM:}

Since each element's properties are measured independently, we can use different material properties for each element, which is a clear advantage. As a result, nearly every level of non-homogeneity can be accommodated. Since the form of the medium is unrestricted, random and irregular forms, as all numerical approximations, pose no problem. The foundation of FEM is the principle of definition. Nonetheless, the technology may be used as a variation or residual solution. Recognizes the multidimensional continuous, but does not necessitate a

\section{Limitations in FEM:}

FEM has progressed to a high degree of growth as a solution technology; however, the approach only produces practical outcomes if simple phenomena are defined by coefficients or material parameters. The fundamental method of subdividing the spectrum of producing errorfree input data for computers is the most boring part of using FEM.

\section{Applications of FEM:}

Originally, the finite element approach was created to analyse aircraft structures. However, because of the general simplicity of the principle, it can be used to solve a broad range found in a jurisdiction or area of a body that meets certain boundary conditions. The best technique for investigating aircraft structures is the finite element approach, which includes. Problems with stress accumulation in mechanical architecture, stress examination of pressure vessels.The finite element approach can be used to efficiently deal with complex study of mechanical linkages.

If the problem is a fluid dynamics problem, stabilization of laminar flows can be found, and resonance properties can be found if the problem The static study of trusses, columns, and bridges is carried out using the finite element approach of structural engineering. The aim of the dynamic analysis is to determine the structure's natural frequencies, modes, and response to periodic loads.

The finite element approach is also used in nuclear engineering to characterize static and dynamic, and reactor component containment structures. Dynamic responses. For impact analysis of skulls, also biomedical engineering uses the finite element approach. Under the heading of Geo mechanics, the finite element approach can be used to analyze excavations, underwater openings, and the complex study of dam reservoir structures.

It solves the problem by reducing a related error function using Finite element methods, which divide a problem domain into smaller parts, and vibrational methods from the calculus of variations.

FEM is a collection of methods for approximating a more complex equation over a wider area by connecting several simple element equations over many small subdomains, known as finite elements. area, similar to how connecting several tiny straight lines would approximate a larger circle.

\section{Linear Static Analysis}

It is the simplest and most commonly used type of analysis

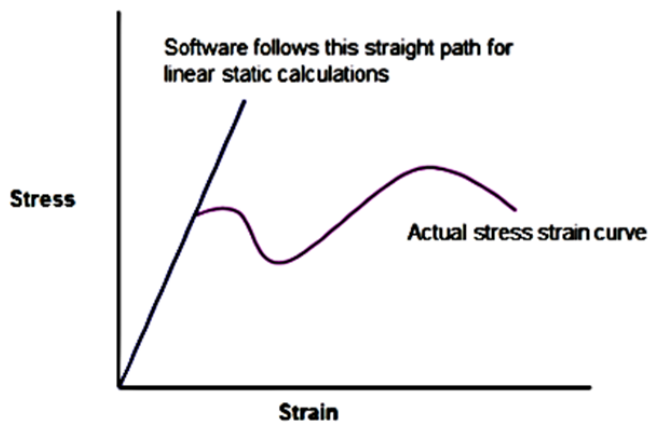

Figure 3. Linear Static Approach

The term "linear" refers to a straight line. $=€ \mathrm{E}$ is the equation of a straight line moving through the origin $(\mathrm{y}=\mathrm{mx}+\mathrm{c})$. Young's modulus, abbreviated as 'E,' is the slope of a curve and is a constant. In real life, content follows a nonlinear curve after reaching the yield point, but software follows the same straight path. After crossing the ultimate tension, the component breaks into two parts, 
but software-based analysis never shows this type of failure.

\section{CONCLUSION}

Studies have shown that hybrid composites have better physical, tri biological electronic and chemical properties than standard composites. The nature and volume fractions of reinforcement, particle size, the degree of uniform distribution of reinforcing particles in the matrix, the manufacturing process, and the heat treatment have all been defined as determinants for improving hybrid composite properties. Hybrid processing allows for the use of a variety of fabrics, both organic and inorganic.

As a result, for the manufacture of aluminium hybrid composites with acceptable properties, the use of cheaper, readily available, and non-long chain reinforcements should be considered.

\section{REFERENCES}

[1] A. Baradeswaran, "Effect of Graphite Content on Tribological behaviour of Aluminium alloy -Graphite Composite". European Journal of

Scientific Research, vol.53 no.2, pp.163-170, 2011.

[2] S. Mitrović, M. Babić, B. Stojanović, N. Miloradović, M. Pantić, D. Džunić, "Tribological Potential of Hybrid Composites Based on Zincand Aluminium Alloys Reinforced with SiC and Graphite Particles", Tribology in Industry, vol. 34, no. 4, pp 177-185, 2012.

[3] K. R. Suresh, H.B. Niranjan, P.M. Jabraj, M.P. Chowdaiah, "Tensile and wear properties of aluminium composites". Wear, vol 255, pp 638-642,

2003.

[4] M.K. Surapa, "Aluminium matrix composites: Challenges and opportunities". Sadhana Vol. 28, Parts 1 \& 2, pp. 319-334, 2003.

[5] R. Ubolluk, C. Prinya, and S. Prasert, "Development of high-volume rice husk ash alumino silicate composites". International Journal of Minerals, Metallurgy and Materials, vol. 17, no. 5, p 654, 2010.

[6] Lancaster L., Lung M. H., and Sujan D. Utilization of Agro- Industrial Waste in Metal Matrix Composites: Towards Sustainability. World Academy of Science, Engineering and Technology. vol. 73 pp1136 - 1139, 2013.

[7] N. Prashant, M. Nagaral and V. Auradi, "Preparation and Evaluation of Mechanical And Wear Properties Of 6061al Reinforced With Graphite Particulate Metal Matrix Composite". International Journal of Metallurgical \& Materials Science and Engineering, vol.2, Issue 3, pp 85 95, 2012.

[8] V.K. Saini, A. K. Zahid, N. S. Arshad, "Advancements in Non- Conventional Machining of Aluminium Metal Matrix Composite materials". International Journal of Engineering Research \& Technology (IJERT) vol. 1, Issue 3, pp 1-14, 2012.

[9] R.H. Pydi, B. Adhithan, A. Bakrudeen, "Microstructure Exploration of the Aluminium-Tungsten
Carbide Composite with different Manufacturing circumstances". International Journal of Soft Computing and Engineering, vol. 2, Issue-6, 2013.

[10] D.Z, Wang, H.X. Peng, J. Liu and C.K. Yao, "Wear Behaviour and Microstructural changes of SiC-Al Composite under unlubricated slidingfriction". Wear, vol. 184, pp. 187-192, 1995.

[11] Garcia-Cordovilla C., Narciso J., and Louis E., "Abrasive wear resistance of aluminum alloy/ceramic particulate composites", Wear, vol. 192, pp. 170-177, 1996

[12] J.S.S. Babu, K.N. Prabhakaran, G. Unnikrishnan, C.G. Kang, "Development of Aluminum-based Hybrid Composites with Graphite Nanofibers/Alumina Short Fibers: Processing and Characterization". Journal of Composite Materials, vol 44, no. 16, pp1929 - 1943, 2010.

[13] K.R Gopi, K.N Mohandas, H.N Reddappa, M.R. Ramesh, "Characterization of As Cast and Heat-Treated Aluminium 6061/Zirconsand/Graphite Particulate Hybrid Composites". International Journal of Engineering and Advanced Technology (IJEAT), vol. 2, Issue 5, pp 340344, 2013.

[14] C.S. Okumu's, S. Aslan, R. Karslioglu, D. Gultekin, H. Akbulut, "Thermal Expansion and Thermal Conductivity Behaviors of Al- Si/sic/graphite Hybrid Metal Matrix Composites (MMCS)". MaterialsScience (MEDŽIAGOTYRA). vol. 18, no. 4. pp 341-346, 2012.

[15] K.K. Alaneme, B.O. Ademilua, M.O. Bodunrin, "Mechanical Properties and Corrosion Behaviour of Aluminium Hybrid Composites Reinforced with Silicon Carbide and Bamboo Leaf Ash". Tribology in Industry, vol. 35, no. 1, pp 25-35, 2013.

[16] M. Mahendra Boopathi, K.P. Arulshri and N. Iyandurai "Evaluation ofmechanical properties of aluminium alloy 2024 reinforced with silicon carbide and fly ash hybrid metal matrix composites". American Journal

of Applied Sciences, vol. 10, no 3, pp 219-229, 2013.

[17] L. Jinfeng, W. Gaohui, Z. Qingbo, D. Zuoyong, H. XiaoLi, "Mechanical properties of $\mathrm{SiC} / \mathrm{Gr} / \mathrm{Al}$ composites fabricated by squeeze castingtechnology". Scripta Materialia, volume 59, Issue 6, pp 619-622, 2008.

[18] D.S Prasad, C. Shoba, N. Ramanaiah, "Investigations on Mechanical Properties of Aluminium Hybrid Composites". Journal of Materials Research and Technology, Issue 70, 2013.

[19] M.N. Rajashekhar and A.R. Anwar Khan, "Studies on Effect of Heat Treatment on Mechanical Properties of Hybrid Aluminium Matrix Composites". International Journal of Innovative Research in Science, Engineering and Technology. vol. 2, Issue 11, pp 6150 - 6157, Nov.

2013.

[20] C. Velmurugan, R. Subramanian, R. Ramakrishnan, T. Kannan, B Anandamela, Experimental Investigations on the effect of heat-treatment parameters on the Wear behaviour of an aluminium hybrid composites,

Industrial Lubrication and Tribology, vol. 66 Issue 4, 2014.

[21] M. Asif, K. Chandra, P.S. Mishra, "Development of Aluminium Based Hybrid Metal Matrix Composites for Heavy Duty Applications". Journal of Minerals \& 
Materials Characterization \& Engineering, vol. 10, no.14, pp.1337-1344, 2011.

[22] A. B. Gurcan and T. N. Baker, "Wear behaviour of AA6061 aluminium alloy and its composites". Wear, vol. 188, pp 185- 191, 1995.

[23] H. H. Fu, K. S. Han and J. I. Song, "Wear properties of Saffil/ Al,Al/Saffil/Al2O3 and Saffil/ SiC/Al hybrid metal matrix composites" .Wear, vol. 256, pp 705-713, 2004.

[24] D. Jun, L. Y. Hui, Y.S. Rong and L.W. Fang, "Dry sliding friction and wear properties of $\mathrm{Al} 2 \mathrm{O} 3$ and carbon short fibres reinforced Al-12Sialloy hybrid composites", Wear, vol. 257, Issues 9-10, pp 930-940,2004.

[25] L.Y. Hui, D. Jun, Y. S. Rong and W. Wei, "High temperature friction and wear behaviour of $\mathrm{Al} 2 \mathrm{O} 3$ and/or carbon short fibre reinforced Al-12Si alloy composites". Wear, vol. 256, Issues 3-4, pp 275-285, 2004.

[26] S. Mahdavi and F. Akhlaghi, "Effect of SiC Content on the Tribological Properties of Hybrid $\mathrm{Al} / \mathrm{SiC} / \mathrm{Gr}$ Composites Processed by in situ Powder Metallurgy (IPM) Method". Adv Mat Res. p1878, 2011.

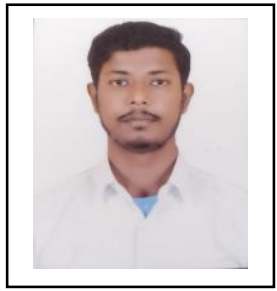

Saroj Kumar is M.Tech Scholar, Department of Mechanical Engineer ,KCCITM Gr. Noida , UP , India. $\mathrm{He}$ had completed B.Tech In Mechanical Engineering from KCC Institute of Technology and Management, Gr Noida, UP, India.

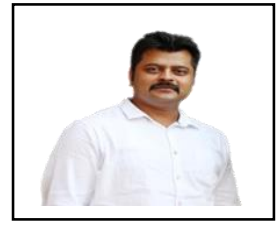

Mr. Keshav Kumar Jha is Assistant Professor in Department of Mechanical Engineering, KCC Institute of Technology and Management Greater Noida, UP. $\mathrm{He}$ is also working as Associate Dean of Student welfare. Area of specialization manufacturing, tribology, IoT, Sensor. Currently member of SAE India, IAENG.
[27] J. Leng, I. Jiang, G. Wu, S. Tian, G. Chen, "Effect of Graphite Particle Reinforcement on Dry Sliding Wear of $\mathrm{SiC} / \mathrm{Gr} / \mathrm{Al}$ Composites". Rare Metal Materials and Engineering, vol. 38, no. 11, 2009.

[28] G.M.L. Ted and T.Y.A Chi, "Tribological behaviours of Aluminium /SiC/nickel-coated graphite hybrid composites". Materials Science and Engineering, vol 33, Issues 1-2, pp134-145, 2002.

[29] W. Ames and A.T Alpas, "Wear Mechanisms in Hybrid Composites ofGraphite-20\% SiC in A356 Aluminium Alloy". Metall Mater Tras A, vol.26, pp 85, 2001.

[30] M. Lagiewka, Z. Konokpka, A. Zyska, M. Nadolski, "Examining of Abrasion Resistance of Hybrid Composites Reinforced with $\mathrm{SiC}$ and $\mathrm{Cg}$ particles". Archives and Foundry Engine, vol. 8, no. 3, pp 59, 2008.

[31] G.M.L. Ted and T.Y.A Chi, "Tribological Behaviour of Self lubricating 